JPE 10-3-15

\title{
Mitigation of Low Frequency AC Ripple in Single-Phase Photovoltaic Power Conditioning Systems
}

\author{
Sang-Hoey Lee*, Tae-Pung An**, and Hanju Cha ${ }^{\dagger}$ \\ $\dagger *$ Dept. of Electrical Engineering, Chungnam National University, Daejeon, Korea \\ ${ }^{* *}$ Entec Electric \& Electronic Co.,Ltd., Hwaseong, Korea
}

\begin{abstract}
A photovoltaic power conditioning system (PV PCS) that contains single-phase dc/ac inverters tends to draw an ac ripple current at twice the output frequency. Such a ripple current perturbs the operating points of solar cells continuously and it may reduce the efficiency of the current based maximum power point tracking technique (CMPPT). In this paper, the ripple current generation in a dc link and boost inductor is analyzed using the ac equivalent circuit of a dc/dc boost converter. A new feed-forward ripple current compensation method to incorporate a current control loop into a $\mathrm{dc} / \mathrm{dc}$ converter for ripple reduction is proposed. The proposed feed-forward compensation method is verified by simulation and experimental results. These results show a $41.8 \%$ reduction in the peak-to peak ac ripple. In addition, the dc/ac inverter control system uses an automatic voltage regulation (AVR) function to mitigate the ac ripple voltage effect in the dc link. A $3 \mathrm{~kW}$ PV PCS prototype has been built and its experimental results are given to verify the effectiveness of the proposed method.
\end{abstract}

Key Words: Automatic voltage regulation, Current based maximum power point tracking, DC/DC converter, Feed-forward ripple current compensation method, Ripple reduction

\section{INTRODUCTION}

Photovoltaic (PV) energy is currently considered to be one of the most useful renewable natural energy sources in the world. However, in the literature, the energy-conversion efficiency of PV arrays is still low, and thus, the maximum power point tracking (MPPT) control technique is required to extract the maximum power from a PV array in order to achieve maximum operating efficiency. Most photovoltaic power conditioning systems (PV PCS) are adapted to voltage based maximum power point tracking (VMPPT) where the voltage reference is generated by dc/dc converter control with incremental conductance or the perturbation and observation method $(\mathrm{P} \& \mathrm{O})$. But VMPPT generates perturbation ripples in the maximum power point (MPP) because of the 2nd-order harmonic ripple reflection and MPPT control perturbation. Therefore MPPT efficiency is reduced by ripples and noise. The proposed current based maximum power point tracking technique (CMPPT) [1] uses a current reference with the modified incremental conductance method. The advantage of CMPPT control has been verified. CMPPT can reduce ripple and achieve the MPP accurately. Therefore the system

\footnotetext{
Manuscript received Jan. 27, 2010; revised Mar. 10, 2010

† Corresponding Author: hjcha@cnu.ac.kr

Tel:+82-42-821-7603, Fax: +82-42-821-8895, Chungnam Nat'1 Univ.

* Dept. of Electrical Engineering, Chungnam National University, Korea

** Entec Electric \& Electronic Co., Ltd., Korea
}

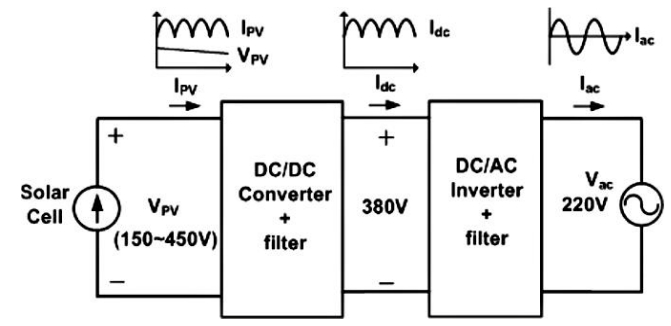

Fig. 1. Block diagram of a single phase PV PCS.

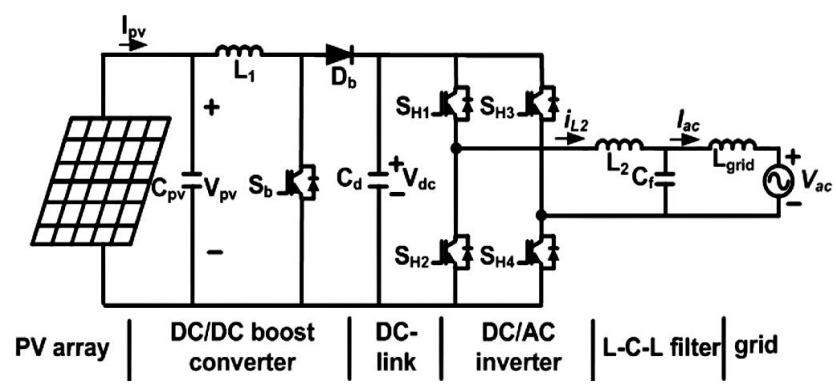

Fig. 2. Transformer-less type PV PCS.

efficiency can be increased. However, the CMPPT also reflects a 2nd-order harmonic ripple to achieve the MPP, which is why a low-frequency ac ripple mitigation method is proposed in this paper. 


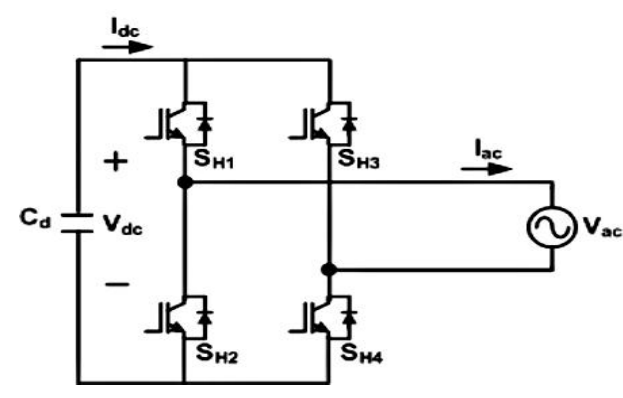

Fig. 3. Dc/ac inverter.

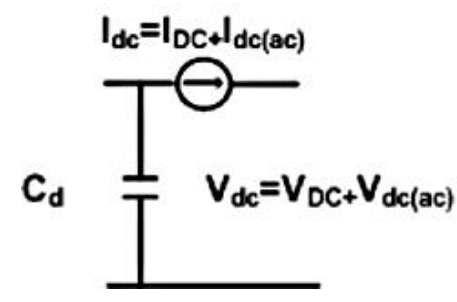

Fig. 4. Dc-Link voltage and current with ripples.

Fig. 1 shows the block diagram of a PCS that contains a $\mathrm{dc} / \mathrm{dc}$ boost converter and a dc/ac inverter. The output of the $\mathrm{dc} / \mathrm{dc}$ converter voltage (the input of dc/ac inverter in the dclink capacitor) is $380 \mathrm{~V}$ and the output of the dc/ac inverter is $220 \mathrm{~V} / 60 \mathrm{~Hz}$ of grid voltage. The dc/ac inverter converts dc-link voltage to ac voltage in order to transfer solar energy to grid voltage. With a linear load, the output current has the same frequency phase and sinusoidal waveform as the grid voltage.

The inverter input voltage and current in the dc link are $\mathrm{dc}$, but the current contains high frequency switching noises and a low frequency ripple component. It contains a $120 \mathrm{~Hz}$ component as shown in Fig. 1. The frequency of the ripple component is $120 \mathrm{~Hz}$, which is twice the output frequency. The output current undergoes a rectification effect through the inverter switches, and thus it appears to be a $120 \mathrm{~Hz}$ pulsating current. The $120 \mathrm{~Hz}$ pulsating current is smoothly filtered by the dc link capacitor but a significant part of the $120 \mathrm{~Hz}$ ripple continues to propagate through the $\mathrm{dc} / \mathrm{dc}$ converter and finally the solar cells.

Although PV PCS control has been studied for about three decades, a good control method for $120 \mathrm{~Hz}$ ripple reduction has not been found for application to a single phase PV PCS. Recently, Dr. Lai proposed an active control technique to reduce ac ripple for fuel cell applications [2], [3]. A $120 \mathrm{~Hz}$ pulsating current also generates a $120 \mathrm{~Hz}$ ripple voltage on the dc link voltage, which causes a distorted ac output current. Reducing the ripple voltage by a programmed pulse-width modulation (PWM) has been proposed [4] and ripple-free dclink voltage was achieved at the expense of large dc-link filter component values [5].

In this paper, a new control method for reducing the $120 \mathrm{~Hz}$ ripple current, which is propagating into a $\mathrm{dc} / \mathrm{dc}$ converter, is proposed for $\mathrm{dc} / \mathrm{dc}$ converters. Also an automatic voltage regulation (AVR) function is employed for dc/ac inverters. Because the $120 \mathrm{~Hz}$ ripple current perturbs the operating points of solar cells, it degrades the MPPT function of a PV PCS and therefore, decreases the MPPT efficiency along with

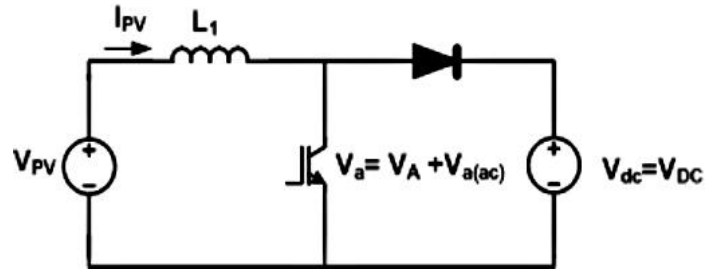

Fig. 5. Dc/dc boost converter (ripple free dc-link).

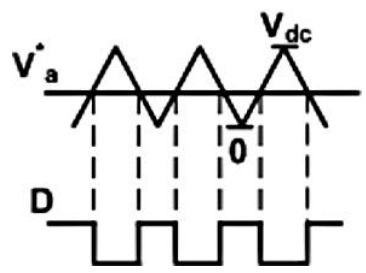

Fig. 6. Duty cycle D generation (ripple free dc lnk).

the entire PCS operation efficiency [6], [7]. Therefore, the proposed control method can increase the operation efficiency. This paper details an analysis of the proposed method. Its feasibilities are verified by simulation and experiments with a $3 \mathrm{~kW}$ PV PCS.

\section{Proposed AC Ripple Mitigation Method}

Fig. 2 shows a commonly used transformer-less type PV PCS for residential use. The PCS is composed of a PV array, a $\mathrm{dc} / \mathrm{dc}$ boost converter, a dc-link, a dc/ac inverter and an L-C-L filter. PV voltage $V_{p v}$ has a wide voltage range, from $150 \mathrm{~V}$ to $400 \mathrm{~V}, \mathrm{dc} / \mathrm{dc}$ boost converter regulated PV current $I_{p v}$, in order to perform a MPPT function. The dc/ac inverter is controlled to generate the grid current with a unity power factor.

\section{A. AC ripple generation in a DC-link}

Fig. 3 shows a single-phase full bridge dc/ac inverter, where the dc-link power from the capacitor $C_{d}$ is used to generate the ac grid $V_{a c}$. The grid voltage $V_{a c}$ and grid current $I_{a c}$ are defined as follows:

$$
\begin{aligned}
& V_{a c}=V_{m} \sin \omega t \\
& I_{a c}=I_{m} \sin \omega t \\
& \text { where, } \quad \omega=2 \pi f .
\end{aligned}
$$

The input power $P_{d c}$ and output ac power $P_{a c}$ of the dc/ac inverter are calculated as:

$$
\begin{aligned}
& P_{d c}=V_{d c} I_{d c} \\
& P_{a c}=V_{m} I_{m} \sin ^{2} \omega t=\frac{V_{m} I_{m}}{2}(1-\cos 2 \omega t) .
\end{aligned}
$$

Since $P_{d c}=P_{a c}$, the dc-link current $I_{d c}$ is derived from (3) and (4). Therefore $I_{d c}$ consists of the dc component $I_{D C}$ and the ac component $I_{d c(a c)}$ like (5).

$$
\begin{aligned}
& I_{d c}=\frac{V_{m} I_{m}}{2 V_{D C}}(1-\cos 2 \omega t)=I_{D C}+I_{d c(a c)} \\
& \text { where, } \quad I_{D C}=\frac{V_{m} I_{m}}{2 V_{D C}} \quad I_{d c(a c)}=-\frac{V_{m} I_{m}}{2 V_{D C}} \cos 2 \omega t
\end{aligned}
$$




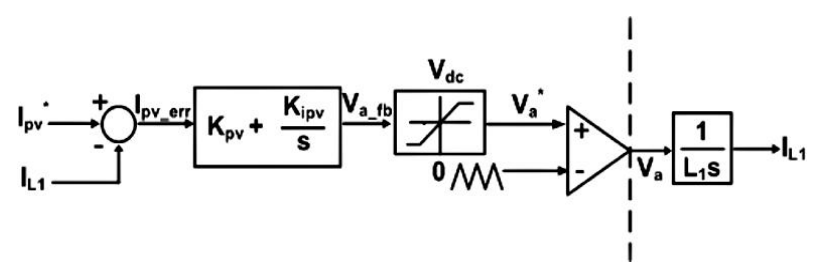

Fig. 7. Conventional control scheme of dc/dc boost converter.

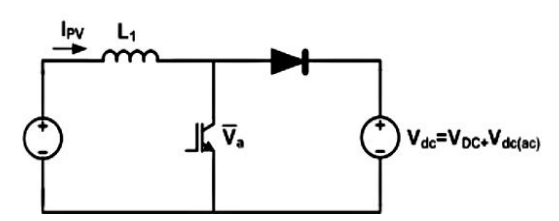

Fig. 8. Dc/dc boost converter (rippled dc link).

Thus, the dc-link voltage ripple $V_{d c(a c)}$ can be calculated by integrating the ac component $I_{d c(a c)}$ as (6) and indicating that $V_{d c(a c)}$ contains a $120 \mathrm{~Hz}$ component with the same phase as the grid voltage $V_{a c}$.

$$
\begin{aligned}
V_{d c(a c)} & =\frac{1}{C} \int-I_{d c(a c)} d t=\frac{V_{m} I_{m}}{2 V_{D C} \cdot C} \frac{1}{2 \omega} \cdot \sin 2 \omega t \\
& =\frac{V_{m} I_{m}}{2 \omega V_{D C}} \cdot \sin 2 \omega t=V_{m(a c)} \sin 2 \omega t
\end{aligned}
$$

Fig. 4 shows the dc-link voltage. $V_{d c}$ and $I_{d c}$ consist of dc and ac components, which are mainly 2nd-order harmonics, respectively.

\section{B. $d c / d c$ converter control with a ripple free dc-link}

Fig. 5 shows a dc/dc boost converter with a ripple free dclink voltage $V_{d c}$. This means that $I_{d c}$ does not have a ripple component, either.

$\mathrm{PV}$ voltage $V_{P V}$ is represented by the voltage gain of a boost converter as:

$$
V_{D C}=\frac{V_{P V}}{1-D}
$$

Thus,

$$
V_{P V}=(1-D) V_{D C}=\bar{V}_{a}
$$

where $\bar{V}_{a}$ is the average value of the voltage across the switch $S_{b}$ in the steady state and $\bar{V}_{a}$ is equal to $V_{P V}$ by ignoring the drop voltage in $L_{1}$ in the steady state.

Fig. 6 shows duty ratio D generation using the common triangular wave comparison method, where the peak value of the triangular wave is $V_{d c}$ and $V_{a}^{*}$ is the command voltage for the dc/dc converter.

Duty cycle $\mathrm{D}$ is generated in Fig. 6 as in (9), where $V_{d c}$ becomes $V_{D C}$ because of the ripple free dc-link condition.

$$
D=\frac{V_{a}^{*}}{V_{D C}} \text {. }
$$

Therefore, $V_{p v}$ and $V_{a}^{*}$ can be calculated as (10) and (11) under the ripple free dc-link condition.

$$
\begin{aligned}
& V_{P V}=\bar{V}_{a}=(1-D) V_{D C}=\left(1-\frac{V_{a}^{*}}{V_{D C}}\right) V_{D C}=V_{D C}-V_{a} \\
& V_{a}^{*}=V_{D C}-\bar{V}_{a}=V_{D C}-(1-D) V_{D C}=D V_{D C} .
\end{aligned}
$$

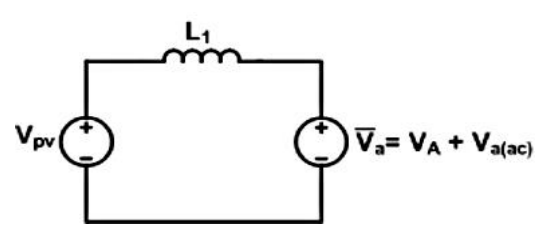

Fig. 9. Equivalent circuit of dc/dc converter (rippled dc link).

(a)
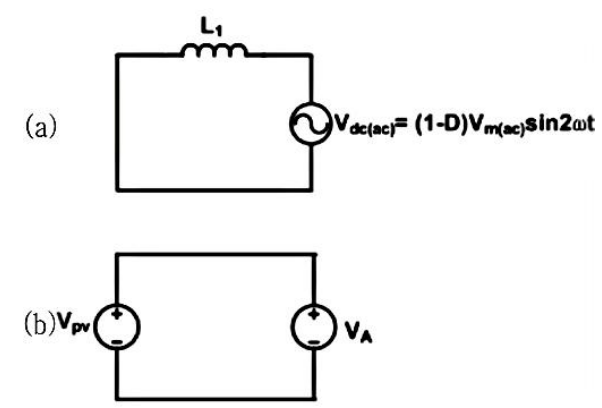

Fig. 10. (a) AC equivalent circuit (b) DC equivalent circuit.

Fig. 7 shows a conventional control scheme for a dc/dc boost converter, where $I_{p v}^{*}$ is calculated from the MPPT function and $V_{a}^{*}$ is equal to the average voltage across the switch $S_{b}$. The transfer function controller is derived such that:

$$
\frac{I_{P V}}{I_{p v}^{*}}=\frac{K_{P V} s+K_{i P V}}{L_{a 1} s^{2}+K_{P V} s+K_{i P V}} .
$$

\section{Dc/dc converter control with a rippled dc-link}

Fig. 8 shows a dc/dc boost converter with a rippled dc link, where $V_{d c}$ has a dc component $V_{D C}$ and an ac component $V_{d c(a c)}$. In this case, the $V_{d c}$ calculation in (6) is rewritten for convenience as:

$$
V_{d c}=V_{D C}+V_{m(a c)} \sin 2 \omega t
$$

By combining (8) and (13) for the rippled dc-link:

$$
\begin{aligned}
\bar{V}_{a} & =(1-D) V_{d c}=(1-D)\left(V_{D C}+V_{m(a c)} \sin 2 \omega t\right) . \\
& =V_{A}+V_{a(a c)}
\end{aligned}
$$

Therefore, the average voltage $\bar{V}_{a}$ is divided into the dc component $V_{A}$ and the ac component $V_{a(a c)}$ as shown in Fig. 9.

By applying the superposition principle to the equivalent circuit in Fig. 9, the ac and dc equivalent components are separated as shown in Fig. 10(a) and (b).

The ripple current $I_{L 1(a c)}$ through the boost inductor $L_{1}$ caused by the $120 \mathrm{~Hz}$ component of the dc-link current $I_{d c(a c)}$ is derived by solving a differential equation for the ac equivalent circuit in Fig. 10(a):

$$
I_{L 1(a c)}=\frac{-(1-D) V_{m(a c)}}{2 \omega L_{1}} \sin \left(2 \omega t-\frac{\pi}{2}\right) .
$$

\section{Proposed feed-forward ripple current compensation}

With the rippled dc link, $V_{D C}$ from (9) is replaced by $V_{d c}$ from (13) and the duty cycle $D$ is derived as:

$$
D=\frac{V_{a}^{*}}{V_{d c}}
$$

$$
\text { where, } \quad V_{d c}=V_{D C}+V_{m(a c)} \sin 2 \omega t
$$




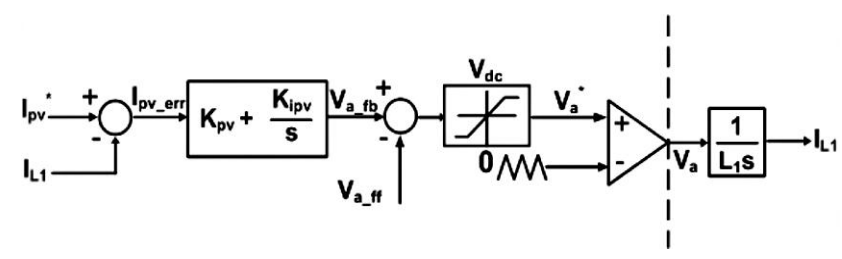

Fig. 11. Proposed dc/dc boost controller with feed-forward compensator.

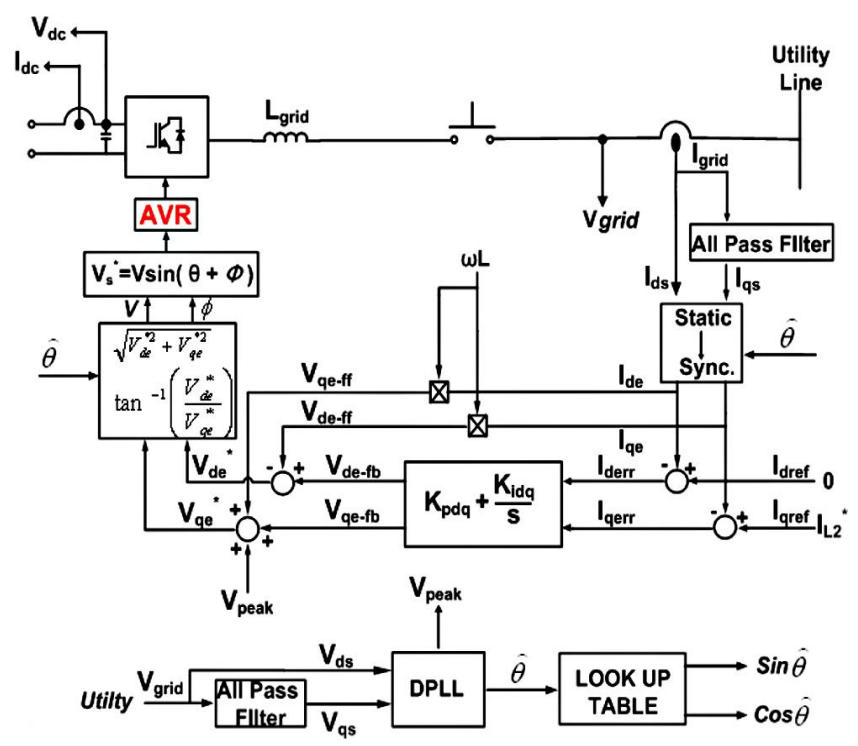

Fig. 12. Dc/ac inverter with AVR function.

If $V_{D C}$ from (8) is replaced by $V_{d c}$ and $D$ from (9) is replaced by (16) then:

$$
\begin{aligned}
V_{p v} & =(1-D) V_{d c}=\left(1-\frac{V_{a}^{*}}{V_{d c}}\right) V_{d c}=V_{d c}-V_{a}^{*} \\
& =V_{D C}+V_{m(a c)} \sin 2 \omega t-V_{a}^{*} .
\end{aligned}
$$

Since $V_{p v}$ contains a $120 \mathrm{~Hz}$ component, the $120 \mathrm{~Hz}$ component can be removed by adding $V_{a_{-} f f}$ term to $V_{a}^{*}$ so that:

$V_{a}^{*}=V_{a_{-} f b}+V_{a_{-} f f}$, where $V_{a_{-} f f}=V_{m(a c)} \sin 2 \omega t$.

Then, the $V_{p v}$ from (17) returns to $V_{P V}$ under the ripple free dc link from (10) as:

$$
\begin{aligned}
V_{p v} & =V_{D C}+V_{m(a c)} \sin 2 \omega t-\left(V_{a_{-} f b}+V_{m(a c)} \sin 2 \omega t\right) \\
& =V_{D C}-V_{a_{-} f b}=V_{P V} .
\end{aligned}
$$

In other words, the feed-forwarded $V_{a \_f f}$, which is $V_{d c(a c)}$ can remove the propagating $120 \mathrm{~Hz}$ current ripple through the $\mathrm{dc} / \mathrm{dc}$ converter. The proposed $\mathrm{dc} / \mathrm{dc}$ converter controller with the feed-forward compensation is shown in Fig. 11.

\section{E. Dclac inverter with AVR}

Fig.12 shows a dc/ac inverter control scheme where the automatic voltage regulation (AVR) function is used to restrict the voltage ripple in the dc-link from propagation to the grid current. A pseudo d-q transformation method is adopted in the inverter control for the grid current. The AVR function is defined in (20), where $V^{*}$ is the command voltage calculated

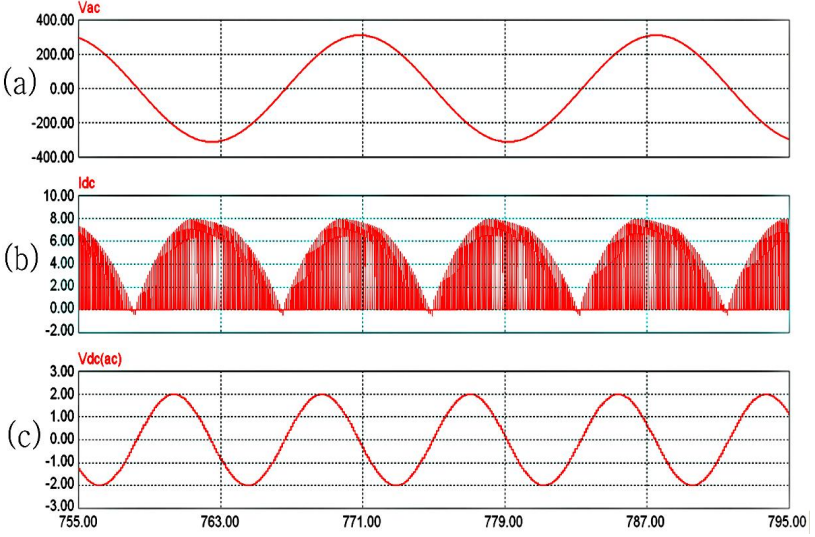

Fig. 13. (a) Utility voltage $V_{A C}$ (b) Dc-link current $I_{d c}$ (c) Dc-link voltage $V_{d c(a c)}$ at $1.2 \mathrm{~kW}$ generation.

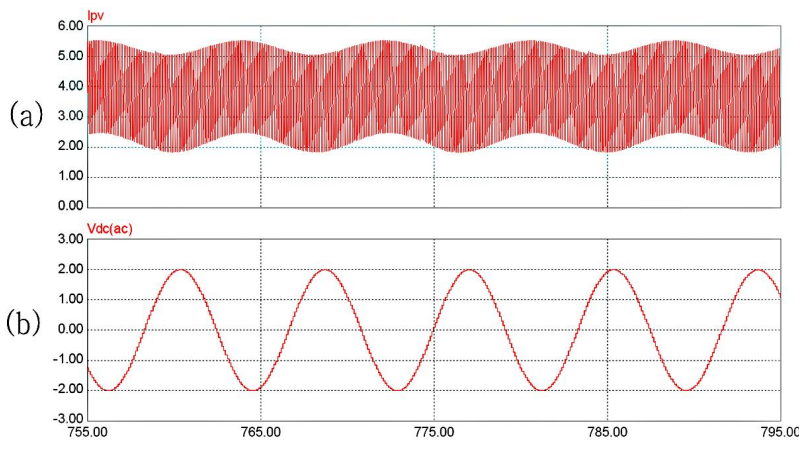

Fig. 14. (a) PV array current $I_{p v}$ (b) dc-link voltage ripple $V_{d c(a c)}$ without compensation.

from the pseudo d-q transformation method and $V_{D C(r e f)}=$ $380 \mathrm{~V}$ is the reference voltage of the dc-link voltage [4].

$$
\begin{aligned}
& V^{*}=\frac{V_{D C(r e f)}}{V_{d c}} * V_{s}^{*}=\frac{\left(V_{D C(r e f)} * V_{s}^{*}\right)}{\left(V_{D C(r e f)}+V_{d c(a c)}\right)} \\
& \text { where, } \quad V_{d c(a c)}=V_{m(a c)} \sin (2 \omega t) .
\end{aligned}
$$

\section{Simulation for AC Ripple Mitigation}

Current control using a pseudo d-q transformation with AVR is simulated by PSIM. $1.2 \mathrm{~kW}$ of power is generated and a $120 \mathrm{~Hz}$ ripple is generated in the dc-link voltage, current and boost inductor current. Fig. 13 shows the grid voltage $V_{a c}$, the dc-link current $I_{d c}$ and the dc-link voltage ripples $V_{d c(a c)}$. The simulated waveforms are well matched with waveforms calculated from the derived equations. Fig. 14 shows the PV array current $I_{p v}$ and the dc-link voltage ripple $V_{d c(a c)}$ without a compensator with gain $\mathrm{kp}=6, \tau=3 \mathrm{~ms}$, where the $I_{p v}$ contains 3.7A of peak-to-peak $120 \mathrm{~Hz}$ ripple current. Fig. 15 shows the same waveforms with the proposed feed-forward compensator and the same gains. It shows that the current ripples are reduced. Therefore, the effectiveness of ripple reduction with the proposed compensator is verified.

\section{EXPERIMENTAL RESULTS}

A prototype of the $3 \mathrm{~kW}$ PV PCS shown in Fig. 16 was built in order to compare the ripple reduction with and without compensation. The $3 \mathrm{~kW}$ PV PCS is implemented fully in the 


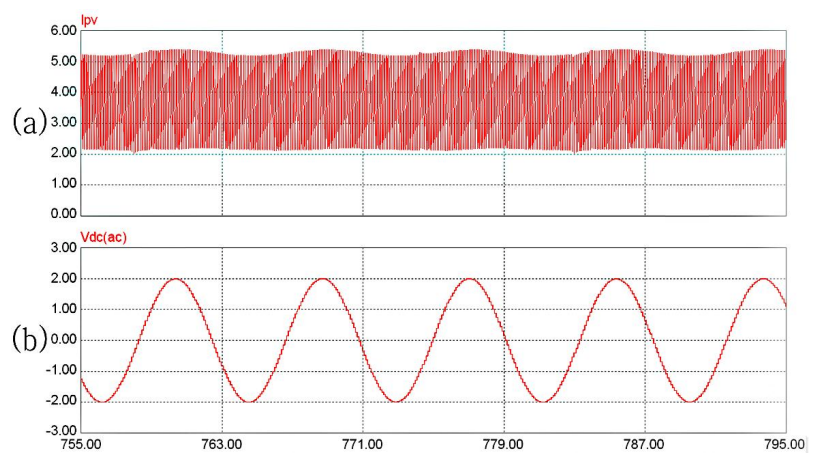

Fig. 15. (a) PV array current with the feed-forward compensation $I_{p v}$ (b) dc-link voltage ripple $V_{d c(a c)}$.

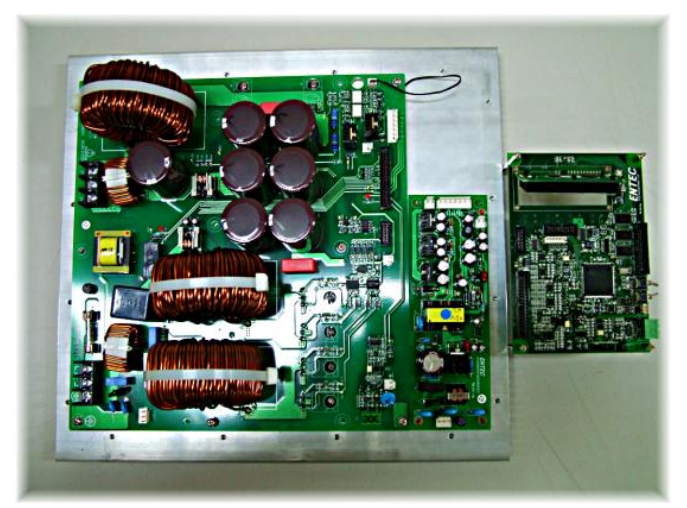

Fig. 16. Prototype of the 3kW PV PCS.

software adopted for a TMS320F2812 digital signal processor. The switching times of each converter are implemented fully in the software, and the voltage and current signals are measured using an internal 12-bit-resolution analog-to-digital converter in the DSP. A digital-to-analog converter is used to display all of the waveforms. The switching frequency of the inverter is $10 \mathrm{kHz}$ and the dead-time is $3 \mu \mathrm{sec}$. Therefore, the output command PWM compensates for the dead time effect.

Fig. 17 shows the PV array current $I_{p v}$. It includes 4A of peak-to-peak ripple with the switching ripple, where the ripple factor is $52.63 \%$ and the dc-link voltage contains $6 \mathrm{~V}$ of peak-to-peak ripple $V_{d c(a c)}$ without compensation (gain $\mathrm{kp}=6$, $\tau=3 \mathrm{~ms}$ ). Therefore the CMPPT cannot achieve high efficiency.

Fig.18 shows the same waveforms with the proposed feedforward compensation. It illustrates a significant reduction in ripples, even with the same gains (gain $\mathrm{kp}=6, \tau=3 \mathrm{~ms}$ ). $I_{p v}$ includes a ripple current with $3 \mathrm{~A}$ of peak-to-peak ripple, where the ripple factor is $39.5 \%$ and $V_{d c}$ includes the same peakto-peak ripple $V_{d c(a c)}$. Therefore, the proposed feed-forward ripple current compensation method significantly reduces the ac ripples in the $\mathrm{dc} / \mathrm{dc}$ converter. It demonstrates a $41.8 \%$ decrease in ripple.

Finally, when generating $3 \mathrm{~kW}$ of power, the PV array current $I_{p v}$ demonstrated a significant reduction of ripples as shown in Fig. 19. It also shows a peak-to-peak ripple $V_{d c(a c)}$ that is just 0.2A and this means that the CMPPT can reach the MPP easily. Hence, the PV PCS efficiency can be increased by reducing the perturbation ripples in the MPP. Fig. 20 shows the grid current $I_{\text {grid }}$ using the AVR function in the dc/ac

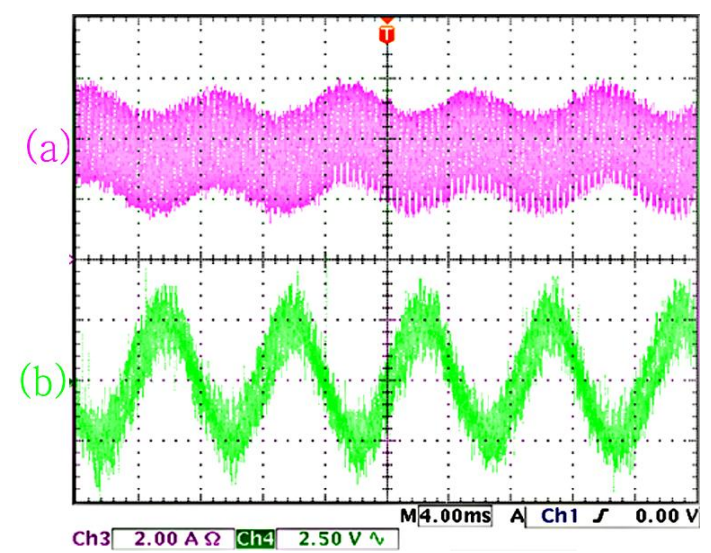

Fig. 17. (a) Current ripple with higher gains $I_{p v}[2 \mathrm{~A} / \mathrm{div}]$ (b) Dc-link voltage ripples $V_{d c(a c)}[2.5 \mathrm{~V} / \mathrm{div}]$.

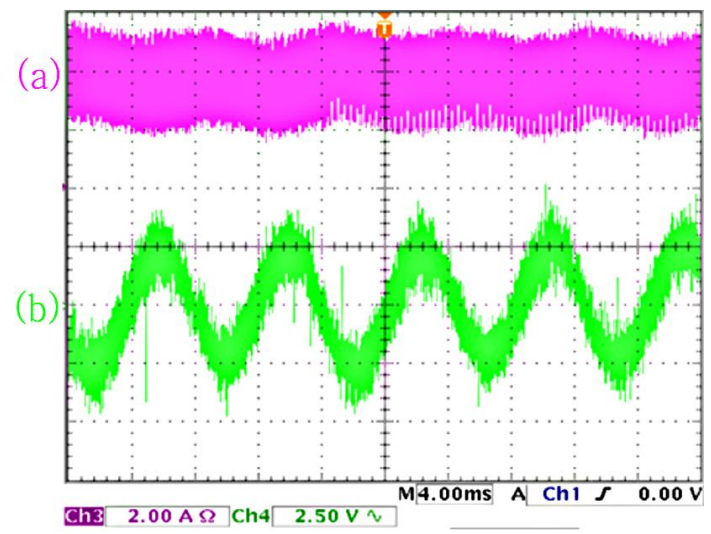

Fig. 18. (a) Current ripple with compensation $I_{p v}[2 \mathrm{~A} / \mathrm{div}]$ (b) Dc-link voltage ripples $V_{d c(a c)}[2.5 \mathrm{~V} / \mathrm{div}]$.

inverter control and it verifies that the dc-link ripple has no effect on the grid current waveform.

\section{CONCLUSIONS}

A PV PCS that contains single-phase dc/ac inverters tends to draw an ac ripple current at twice the output frequency. Such a ripple current perturbs the operating points of the solar cells continuously and it may reduce current based maximum power point tracking (CMPPT) efficiency. In this paper, the ripple current generation in the dc-link and boost inductor has been analyzed using an ac equivalent circuit of the $\mathrm{dc} / \mathrm{dc}$ boost

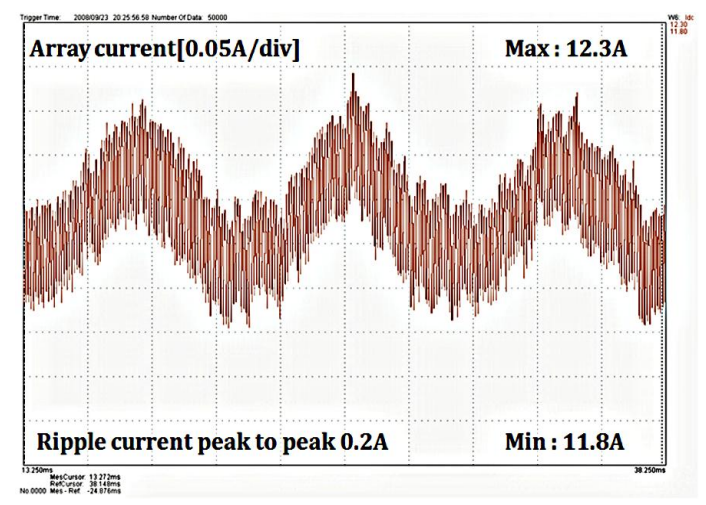

Fig. 19. Array current ripples $3 \mathrm{~kW}$ generation $I_{p v}[0.05 \mathrm{~A} / \mathrm{div}]$. 


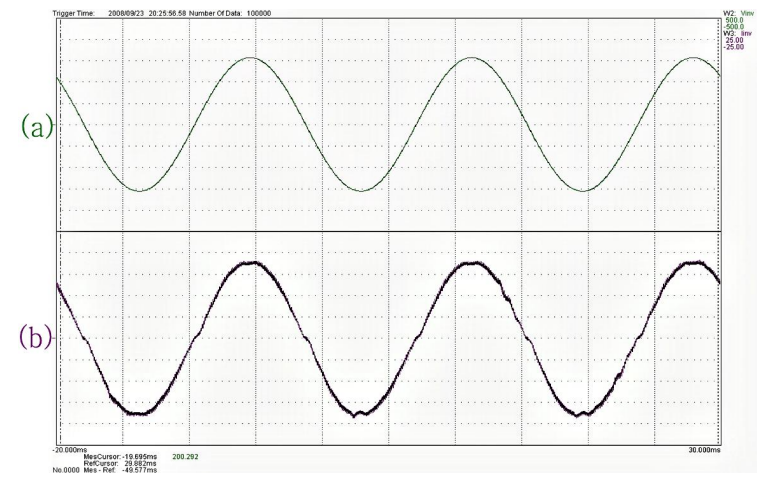

Fig. 20. Grid current control with AVR at $3 \mathrm{~kW}$ generation (a) Grid voltage $V_{\text {grid }}[50 \mathrm{~V} / \mathrm{div}]$ (b) Grid current $\left.I_{\text {grid }}[2.5 \mathrm{~A} / \mathrm{div}]\right)$.

converter. A new feed-forward ripple current compensation method has been proposed to incorporate a current control loop into the $\mathrm{dc} / \mathrm{dc}$ converter control for ripple reduction. The proposed method has been verified in both simulation and experiments. It shows a $41.8 \%$ reduction in peak-to peak ac ripple. In addition, the dc/ac inverter has includes the AVR function to mitigate the effect of the ac ripple voltage on the grid current. A $3 \mathrm{~kW}$ PV PCS has been built and its experimental results verify the effectiveness of the proposed method.

\section{ACKNOWLEDGMENT}

This work was financially supported by the Advanced Human Resource Development Program of MKE through the Research Center for Intelligent Microgrid at Myongji University.

\section{REFERENCES}

[1] H. Cha, S. Lee, "Design and implementation of photovoltaic power conditioning system using a current based maximum power point tracking," in Proc. IEEE-IAS Annual Meeting, pp. 1-5, Oct. 2008.

[2] C Liu, J Lai, "Low frequency current ripple reduction technique with active control in a fuel cell power system with inverter load," IEEE Transactions on Power Electronics, Vol. 22, No. 4, pp.1429-1436, Jul. 2007.

[3] Enjeti, P.N., Shireen, W., "new technique to reject dc-link voltage ripple for inverters operating on programmed PWM waveforms," IEEE Transactions on Power Electronics, Vol. 7, No. 1, pp.171-180, Jan. 1992.
[4] P. D. Ziogas et al., "Rectifier-inverter frequency changer with suppressed dc-link components," IEEE Transactions On Industrial Electronics, Vol. 22, No. 6, pp. 1027-1036, Nov. 1986.

[5] S. M. Alghuwainem, "Matching of a dc motor to a photovoltaic generator using a step-up converter with a current-locked loop," IEEE Transactions on Energy Conversion, Vol. 9, No 1, pp. 192-198, Mar. 1994.

[6] M.A.S. Masoum, H. Dehbonei, E.F. Fuchs, "Theoretical and experimental analyses of photovoltaic systems with voltage and current-based maximum power-point tracking," IEEE Transactions on Energy Conversion, Vol. 17, No. 4, pp. 514-522, Dec. 2002.

[7] M.A.S. Masoum, H. Dehbonei, E.F. Fuchs, "Theoretical and experimental analyses of photovoltaic systems with voltage and current-based maximum power-point tracking," IEEE Transactions on Energy Conversion, Vol. 17, No. 4, pp. 514-522, Dec. 2002.

[8] V.Blasko, V.Kaura, "Operation of a phase locked loop system under distorted utility conditions," IEEE Transactions on Industrial Electronics, Vol. 33, No. 1, pp. 58-63, Jan./Feb. 1997.

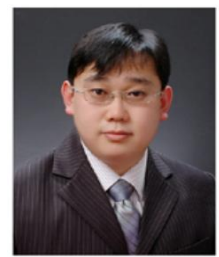

Sang-Hoey Lee was born in Korea in 1977. He received his B.S in Instrumentation Control Engineering from Konyang University, Korea, in 2002, and his M.S. in Electrical Engineering from Chungnam National University, Korea, in 2005. From 2005 to 2007, he worked at the Institute for Advanced Engineering Yongin, Korea. He is currently pursuing his $\mathrm{PhD}$ in Electrical Engineering at Chungnam National University, Daejeon, Korea. His research interests are in power quality, advanced converters and control for renewable energy systems and microgrids.

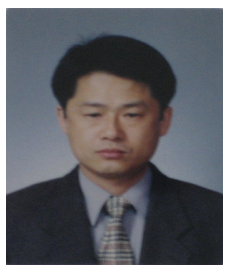

Tae-Pung An was born in Jeongeup, North Jeolla Province, Korea, in 1964. He majored Electronics at Sungkyunkwan University in 1992 and worked in the ILJIN R\&D Dept. in the field of Protection Relay and Communication until 1996. Currently, he works at Entec Electric \& Electronic Co.,Ltd. He is in charge of the Protection Relay Communication R\&D Dept., developing SCADA, DAS, SMART GRID, LOOP CONTROL SYSTEM. His current interests are Power/Distribution, DAS, Power IT, SMART GRID, and new \& renewable energy.

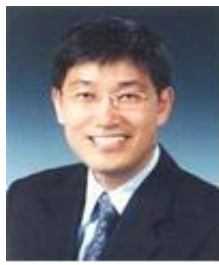

Hanju Cha received his B.S. in Electrical Engineering from Seoul National University, Korea, his M.S. from Pohang Institute of Science and Technology, Korea and his $\mathrm{PhD}$ from Texas A\&M University, College station, TX in 1988, 1990 and 2004, all in Electrical Engineering. From 1990 to 2001, he was with LG Industrial Systems, Anyang, Korea, where he was engaged in the development of power electronics and adjustable speed drives. In 2005, he joined the Department of Electrical Engineering, Chungnam National University, Daejeon, Korea. He worked as a Visiting Professor in United Technology Research Center, Hartford CT, USA in 2009. His research interests are high power dc-dc converters, ac/dc, dc/ac and ac/ac converter topologies, power quality and utility interface issues for distributed energy systems and micro-grids. 